\title{
Evaluation of the Risk of Development of Fluopicolide Resistance in Phytophthora erythroseptica
}

\author{
Xuemei Zhang, He Jiang, and Jianjun Hao, ${ }^{\dagger}$ School of Food and Agriculture, the University of Maine, Orono, ME 04469
}

\begin{abstract}
Fluopicolide has shown effective pink rot (Phytophthora erythroseptica) control in potato disease management. To efficiently utilize this chemical, the risk of fluopicolide resistance in $P$. erythroseptica needs to be assessed. In this study, 34 isolates of $P$. erythroseptica were obtained from symptomatic potato tubers with pink rot in Maine. The sensitivity of these wild-type isolates to fluopicolide was assessed by culturing them on agar medium amended with fluopicolide at various concentrations. The $50 \%$ effective concentration $\left(\mathrm{EC}_{50}\right)$ of fluopicolide for the inhibition of mycelial growth was determined and used to establish a baseline sensitivity of these P. erythroseptica isolates to fluopicolide. The wild-type isolates were sensitive to fluopicolide, with $\mathrm{EC}_{50}$ values ranging from

0.08 to $0.35 \mu \mathrm{g} / \mathrm{ml}$. By exposing $P$. erythroseptica zoospores to agar medium containing $100 \mu \mathrm{g} / \mathrm{ml}$ fluopicolide, 6 out of the 34 wild-type isolates produced fluopicolide-resistant mutants. The mutants were transferred to fungicide-free V8 medium consecutively for 10 times, and the 10th transfer of mutants was examined for resistance stability and biological fitness. In general, the mutants had similar or slower growth rates compared with their wild-type parents, and the virulence of some mutants was significantly reduced. The results indicated a low to moderate risk of $P$. erythroseptica developing resistance to fluopicolide, and suggested a trade-off between fluopicolide resistance and biological fitness in $P$. erythroseptica.
\end{abstract}

Pink rot (Phytophthora erythroseptica) is an economically important disease of potato (Fiers et al. 2012; Pethybridge 1913; Porter et al. 2007; Taylor et al. 2011) causing significant tuber losses in the field and storage (Al-Mughrabi et al. 2007; Mills et al. 2005; Schisler et al. 2009). Pink rot has been managed chemically (Benson 2008), and it used to be managed effectively with the systemic chemical mefenoxam (Wicks et al. 2000). However, the development of mefenoxam-insensitive populations of $P$. erythroseptica has reduced the efficacy of mefenoxam (Goodwin and McGrath 1995; Lambert and Salas 1994; Taylor et al. 2002). As long as chemical products are used, fungicide resistance is always a concern.

Fluopicolide has been proved to be effective for pink rot control (Zhang et al. 2016), as well as a wide range of oomycete pathogens (Jackson et al. 2010; Lu et al. 2011; Rekanovic et al. 2008). The generic name of fluopicolide is 2,6-dichloro- $\mathrm{N}$-[[3-chloro-5-(trifluoromethyl)2-pyridinyl]methyl] benzamide $\left(\mathrm{C}_{14} \mathrm{H}_{8} \mathrm{Cl}_{3} \mathrm{~F}_{3} \mathrm{~N}_{2} \mathrm{O}\right)$. Like other benzamides, fluopicolide acts on cytoskeleton and motor proteins, but it is categorized in B5 group on FRAC (Fungicide Resistance Action Committee) code list with a unique mode of action, delocalizing spectrin-like proteins (FRAC 2018; Toquin et al. 2008). This mode of action differs from other oomyceticides in that it can inhibit isolates that are resistant to phenylamides, strobilurin, dimethomorph, and iprovalicarb (Toquin et al. 2012).

To study the risk of resistance in oomycetes, mutants resistant to fluopicolide have been generated under laboratory conditions. For example, fluopicolide-resistant mutants of Phytophthora capsici were selected from zoospores of wild-type isolates on fluopicolideamended agar media (Lu et al. 2011), and in Pseudoperonospora cubensis induced by UV radiation (Wang et al. 2014). However,

Current address of X. Zhang: Southern Piedmont Agricultural Research and Extension Center, Blackstone, VA 23824; School of Plant and Environmental Sciences, Virginia Tech, Blacksburg, VA 24061.

${ }^{\dagger}$ Corresponding author: J. Hao; E-mail: Jianjun.hao1@maine.edu

Funding: This study was partially supported by Maine Potato Board, USDA IR-4 (2014-34383-22028), USDA-NIFA Multistate Project ME031415, and USDA-NIFA Hatch Project ME021508.

Accepted for publication 3 August 2018.

C 2019 The American Phytopathological Society the risk of fluopicolide resistance in P. erythroseptica remains unknown.

A risk assessment of the likely development of resistance is based on many biological characteristics, such as frequency of mutation, fitness, and virulence. A trade-off between resistance development and biological fitness may occur in plants, bacteria, and fungi (Brown and Rant 2013; Kang and Park 2010; Montarry et al. 2007). Kang and Park (2010) showed that there was a fitness cost to gain antibiotic resistance in bacteria Acinetobacter sp. Fluopicolide-resistant Pseudoperonospora cubensis mutants showed differences with their wildtype parents in latent period, infection frequency, lesion extension, and sporulation (Wang et al. 2014). However, in most cases, there was no difference between most fluopicolide-resistant Phytophthora capsici mutants and their wild-type parents in zoospore production, cyst germination, or virulence (Lu et al. 2011).

The present study aimed to determine the risks of $P$. erythroseptica isolates in developing resistance to fluopicolide and to assess the biological fitness of the resistant mutants. The objectives of this study were to: 1 ) investigate the baseline sensitivity of wild-type $P$. erythroseptica population to fluopicolide, 2) examine the biology and fitness of fluopicolide-resistant isolates, and 3) test the pathogenicity and virulence of the mutants.

\section{Materials and Methods}

Cultures and chemicals. All the experiments were conducted at the University of Maine, Orono. A total of 34 isolates of $P$. erythroseptica were isolated from potato tubers showing pink rot symptoms. The samples were obtained from Maine potato fields (Aroostook County, ME), where there was no history of fluopicolide application. Tuber pieces with partial healthy tissue and rotten lesions were cut (around $1 \mathrm{~cm}$ in length) and surface-sterilized in $75 \%$ ethanol for $30 \mathrm{~s}$, and then soaked in $0.6 \%$ sodium hypochlorite for $5 \mathrm{~min}$, followed by rinsing three times in sterile distilled water. The disinfested tuber pieces were air-dried on sterile filter paper and then placed on a $1.5 \%$ water agar plate. The resultant cultures were purified through the single-spore method (Choi et al. 1999). Isolates 1 to 15 were collected prior to 2013 by Dr. David Lambert at the University of Maine. Isolates 16 and 17 were collected in 2014 and isolates 18 to 34 were collected in 2016. All isolates were originally from Maine. The taxonomy of the isolates was confirmed by analysis of DNA sequences on the internal transcription spacer, which was amplified with polymerase chain reaction (PCR) with primers ITS1 and ITS4. Thermal cycler settings were as follows: $94^{\circ} \mathrm{C}$ for $5 \mathrm{~min}$, followed by $40 \mathrm{cy}$ cles at $94^{\circ} \mathrm{C}$ for $1 \mathrm{~min}, 55^{\circ} \mathrm{C}$ for $1 \mathrm{~min}$, and $72^{\circ} \mathrm{C}$ for $2 \mathrm{~min}$, and ended 
with a 7-min extension at $72^{\circ} \mathrm{C}$ (Villa et al. 2006; White et al. 1990). The sequences of the isolates were analyzed in NCBI database using BLAST algorithm, and confirmed as P. erythroseptica, with both coverage and similarity being above $98 \%$. The sensitivity of all $P$. erythroseptica isolates to mefenoxam was determined prior to this study. Among the collected wild-type $P$. erythroseptica, 13 isolates were mefenoxam resistant $\left(\mathrm{EC}_{50}>10 \mu \mathrm{g} / \mathrm{ml}\right)$, including 13A05, $13 \mathrm{~A} 07$, and 13A39. Five isolates were not determined on mefenoxam sensitivity $\left(\mathrm{EC}_{50}<10 \mu \mathrm{g} / \mathrm{ml}\right)$. The rest (16 isolates) were mefenoxam sensitive, including 13A02, 13A03, and 13A14.

Technical grade of fluopicolide (99.1\% active ingredient) was provided by Valent U.S.A. Corporation (Walnut Creek, USA), and mefenoxam was provided by Syngenta (Greensboro, NC). The chemicals were dissolved in dimethyl sulfoxide (DMSO) and adjusted to a stock concentration $(10,000 \mu \mathrm{g} / \mathrm{ml})$ and working concentration $(1,000 \mu \mathrm{g} / \mathrm{ml})$ for later use.

Sensitivity of $\boldsymbol{P}$. erythroseptica to fluopicolide. The sensitivity of $P$. erythroseptica to fluopicolide was conducted using Autoplate 4000 (Spiral Biotech Inc., Norwood, MA, USA), following the spiral plating method by Förster et al. (2004) with modifications. Briefly, $P$. erythroseptica was incubated on the center of a clarified V8 $(200 \mathrm{ml}$ clarified V8 juice, $2.5 \mathrm{~g} \mathrm{CaCO}_{3}, 1.5 \%$ agar, $800 \mathrm{ml}$ distilled water) plate. Prior to this, cellophane strips $(0.5 \times 3 \mathrm{~cm})$ were autoclaved in distilled water for $15 \mathrm{~min}$ at $121^{\circ} \mathrm{C}$, and were then placed on the V8 plate side by side. The cultures were incubated at $25^{\circ} \mathrm{C}$ in an incubator until all the cellophane strips were covered by mycelia.

To prepare fungicide-amended agar plates, $50 \mathrm{ml}$ potato dextrose agar (PDA) was poured into a $15-\mathrm{mm}$ Petri dish. A 50- $\mu$ l aliquot of fluopicolide $(1,000 \mu \mathrm{g} / \mathrm{ml})$ was distributed to each PDA plate using the autoplate with the exponential mode (Förster et al. 2004). The plates were left in a sterile hood for $30 \mathrm{~min}$ to ensure fungicide absorbance. The mycelia-colonized cellophane strips were moved from the V8 plate and placed on the fluopicolide-amended PDA plates, which were arranged radially (Förster et al. 2004; Torres-Londoño et al. 2016). Two replicated strips from each isolate were arranged diagonally on the plate, and strips of 8 isolates were placed on one PDA plate. Two or three days later, the minimum inhibition concentration (MIC, defined as the chemical concentration at which the pathogen growth is significantly reduced) and total inhibition concentration (TIC, defined as the chemical concentration at which pathogen growth is completely suppressed) were recorded (Förster et al. 2004; Torres-Londoño et al. 2016). The ECX package was used to calculate the $\mathrm{EC}_{50}$ values (Torres-Londoño et al. 2016). Baseline sensitivity of $P$. erythroseptica to fluopicolide was determined based on the sensitivities of all $P$. erythroseptica isolates in this study.

Selection of fluopicolide-resistant $\boldsymbol{P}$. erythroseptica. Zoospores of $P$. erythroseptica were produced based on the methods by $\mathrm{Al}-$ Mughrabi et al. (2007) and Jiang (2017) with a slight modification. Briefly, P. erythroseptica was cultured on 10\% V8 agar for 6 days at $22 \pm 1{ }^{\circ} \mathrm{C}$ in the dark. Mycelial plugs were punched with a 5-mm cork borer and transferred to a Petri plate (10 mm diameter) containing lima bean broth (LBB), with 4 plugs per plate. After being incubated at $22 \pm 1{ }^{\circ} \mathrm{C}$ under natural light for 3 days, LBB was discarded. The original (10\% V8) agar plugs were removed, and the mycelial mats were rinsed with sterilized distilled water three times. The plate with washed mycelial mats was filled with $10 \mathrm{ml}$ of $10 \%$ soil extract and incubated at $18^{\circ} \mathrm{C}$ under continuous fluorescent light. Four days later, the soil extract was discarded and the plate with mycelial mats was triple-rinsed and refilled by $7 \mathrm{ml}$ of chilled $\left(4^{\circ} \mathrm{C}\right)$ sterile water. The plate was chilled at $4^{\circ} \mathrm{C}$ for an hour and then left at $22^{\circ} \mathrm{C}$ for $30 \mathrm{~min}$. Zoospore concentrations of the suspension were estimated with a hemocytometer.

To obtain fluopicolide-resistant mutants of $P$. erythroseptica, V8 agar was amended with fluopicolide at $100 \mu \mathrm{g} / \mathrm{ml}$, subsequently referred to as F-V8. Zoospores of wild-type $P$. erythroseptica isolates were plated with a sterile spreader on F-V8 medium. The final concentration of DMSO in the medium was adjusted to $0.1 \%$. One milliliter of zoospore suspension $\left(10^{4}\right.$ to $10^{5}$ spores $\left./ \mathrm{ml}\right)$ of wild-type isolates was spread on a F-V8 plate. After the plates were incubated at $25^{\circ} \mathrm{C}$ in the dark for 5 days, colonies growing on F-V8 plates were considered as fluopicolide-resistant mutants (Lu et al. 2011). Each isolate had 5 replications, and the experiment was conducted twice. Survival/mutation frequency was calculated as the total number of mutant colonies divided by total number of zoospores on the plate. These mutants were used throughout the study.

Morphological observation and characterization of fluopicolideresistant mutants of $\boldsymbol{P}$. erythroseptica. Morphology. The mutants from F-V8 plates were transferred to a fungicide-free clarified V8 agar plate. When the colony grew to the size of a quarter of a Petri plate, mycelia was cut from the colony edge and transferred to a new V8 plate, which was repeated 10 times. The cultures from the first transfer were referred to as the first transfer of resistant isolates/ mutants (T1). The morphology of wild-type and mutant isolates were observed under a light microscope (Leica Microsystems Inc., Buffalo Grove, IL, USA).

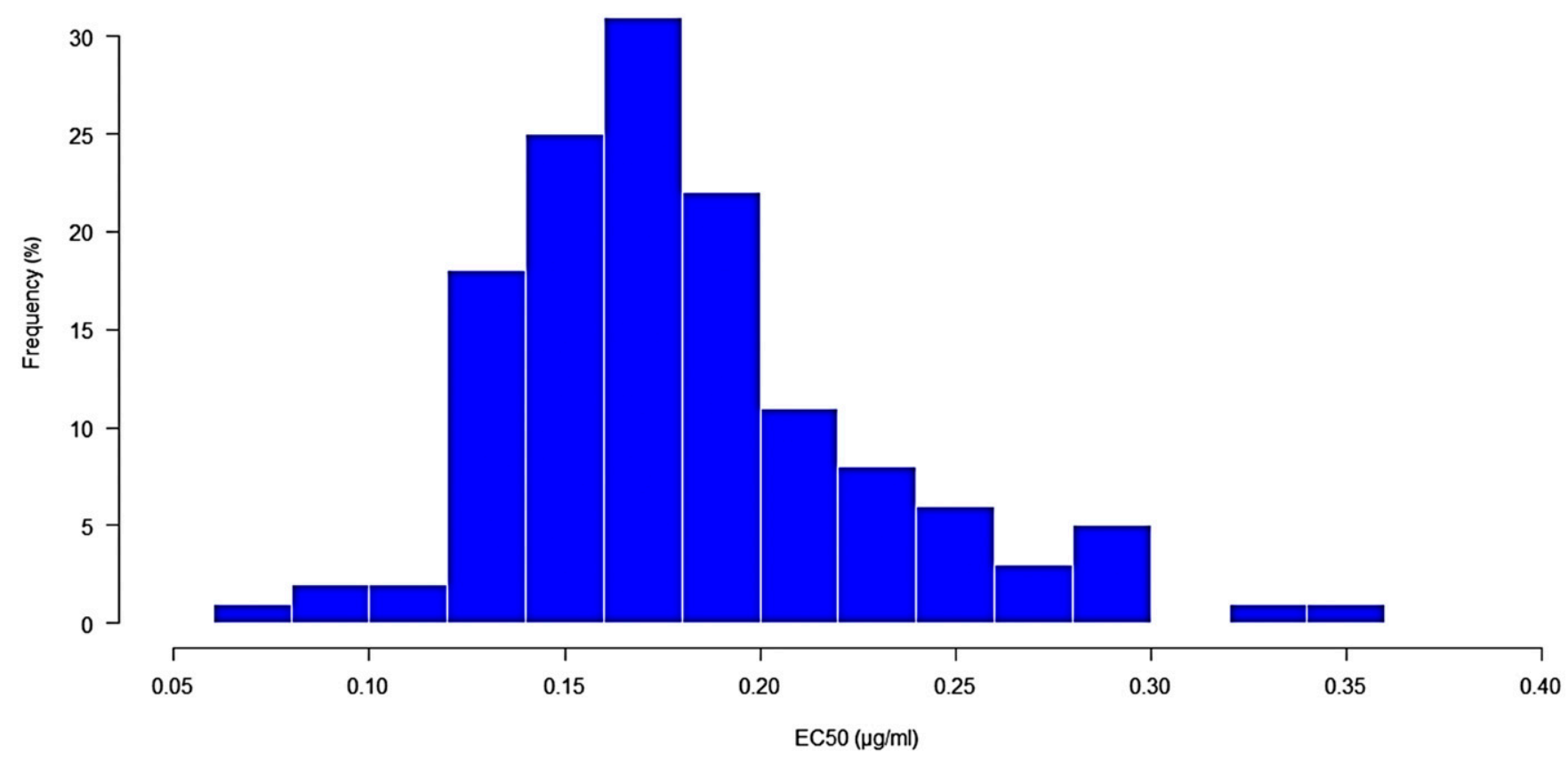

Fig. 1. Distribution of fluopicolide sensitivity of 34 Phytophthora erythroseptica isolates from Maine. $\mathrm{EC}_{50}$ : effective concentration of $50 \%$ inhibition of mycelial growth. 
Mycelial growth of P. erythroseptica mutants. The 10th transfer of $P$. erythroseptica mutants was used to investigate the mycelial growth to compare the differences between fluopicolide-resistant and their wild-type parents. An agar plug was cut with a 5-mm cork borer and transferred from each active culture of $P$. erythroseptica isolate onto a clarified V8 agar plate. All the test isolates were incubated at $28^{\circ} \mathrm{C}$ in the dark. Each isolate had 4 replications. The radius of mycelial growth on each plate was measured at $24,48,72$, and $96 \mathrm{~h}$ of incubation. The original agar plug radius $(5 \mathrm{~mm})$ was subtracted before data analysis. Mycelial growth at $24 \mathrm{~h}$ was used to compare the growth difference between mutants and wild-type parents in the first $24 \mathrm{~h}$ of incubation. Growth curves of the cultures were generated based on the measurements. This assay was repeated once.

Pathogenicity and virulence of $P$. erythroseptica mutants. Disease-free potato ('Russet Norkotah') tubers were used to examine the pathogenicity and virulence of $P$. erythroseptica isolates. The tubers were washed and disinfested with $0.6 \%$ sodium hypochlorite followed by rinses in sterile water. The 10th transfer of fluopicolide-resistant $P$. erythroseptica mutants and their wild-type parents was used for inoculation. Three V8 agar plugs of each isolate were placed on tuber eyes and covered by a cap of a 2-ml Eppendorf tube, which was wrapped with a piece of Parafilm. The treated tubers were suspended on a plastic mesh rack above a wet paper towel in an enclosed sterile plastic container. Tubers treated with pathogen-free agar plugs were used for the control. The tubers were incubated at $25^{\circ} \mathrm{C}$. A completely randomized design with 4 replications was used in this experiment. Seven days after inoculation, all the tubers were

Table 1. Effective concentration of $50 \%$ inhibition $\left(\mathrm{EC}_{50}, \mu \mathrm{g} / \mathrm{ml}\right)$ of mycelial growth of fluopicolide-resistant mutants and wild-type parents of Phytophthora erythroseptica

\begin{tabular}{lcccccc}
\hline Type $^{y}$ & 13A02 & 13A05 & 13A06 & 13A07 & 13A14 & 13A39 \\
\hline Wild-type & $0.16 \mathrm{a}^{\mathrm{z}}$ & $0.18 \mathrm{a}$ & $0.22 \mathrm{a}$ & $0.25 \mathrm{a}$ & $0.20 \mathrm{a}$ & $0.18 \mathrm{a}$ \\
Mutant-1 & - & $0.47 \mathrm{~b}$ & $0.94 \mathrm{~b}$ & $0.41 \mathrm{~b}$ & - & $0.44 \mathrm{~b}$ \\
Mutant-2 & $0.99 \mathrm{~b}$ & $1.29 \mathrm{c}$ & - & - & $>5.31 \mathrm{~b}$ & - \\
\hline
\end{tabular}

y Mutant-1 indicates the type of mutants having $\mathrm{EC}_{50}$ higher but not more than 5 times higher than wild-type parents. Mutant- 2 indicates mutants having $\mathrm{EC}_{50}$ over 5 times higher than the wild-type parents.

${ }^{\mathrm{z}}$ Mean values not connected by the same letters are significantly different $(P<0.05)$ within each column. "-" indicates no data were available. cut from the point of inoculation, and the depth and width (using the inoculation site as the center) of pink lesions were measured. The pathogenicity was confirmed by the presence of pink rot lesions, and the virulence was indicated by tuber lesion penetration. Tuber lesion penetration was calculated by the equation lesion penetration $=$ (depth + width/2)/2 (Fitzpatrick-Peabody and Lambert 2011).

Statistical analysis. EXC was used in data analysis to calculate $\mathrm{EC}_{50}$ (Torres-Londoño et al. 2016). $\mathrm{R}$ version 3.2.3 (R Foundation for Statistical Computing, Vienna, Austria) was used to perform ANOVA and Fisher's LSD (for parametric data) or Wilcoxon each pair analysis (nonparametric data) in fluopicolide sensitivity, mycelial growth, and virulence. Bivariate analysis was used to examine the linear regression fit of mycelial growth rates between 24 and $96 \mathrm{~h}$ of incubation (Everitt 1995; Matthews et al. 1990). Significance level $\alpha$ was set at 0.05 for all data analyses.

\section{Results}

Baseline sensitivity of $\boldsymbol{P}$. erythroseptica to fluopicolide. Frequency of mutation. All 34 wild-type $P$. erythroseptica isolates were sensitive to fluopicolide, which showed a skewed distribution (Fig. 1). The effective concentration for $50 \%$ inhibition of mycelial growth $\left(\mathrm{EC}_{50}\right)$ of those isolates ranged from 0.08 to $0.35 \mu \mathrm{g} / \mathrm{ml}$, with a mean of $0.18 \mu \mathrm{g} / \mathrm{ml}$ and median of $0.17 \mu \mathrm{g} / \mathrm{ml}$. The standard deviation was 0.05 and the coefficient of variation was $25.93 \%$.

Fluopicolide-resistant $\boldsymbol{P}$. erythroseptica mutants. By picking mycelial colonies on F-V8 plates that were plated with zoospore suspensions, a total number of 7 fluopicolide-resistant mutants was obtained from 6 out of 34 isolates of $P$. erythroseptica (Table 1). There were two types of mutants based on $\mathrm{EC}_{50}$, including type-1 mutants which had $\mathrm{EC}_{50}$ higher but less than 5 times higher than their wild-type parents, and type- 2 mutants which had $\mathrm{EC}_{50}$ at least 5 times higher than their wild-type parents. The mutation frequency was between $10^{-5}$ and $10^{-4}$.

Morphology and resistance stability of fluopicolide-resistant $P$. erythroseptica mutants. After transferring to fungicide-free V8 plates, all the mutants grew and formed colonies. However, their morphology was different compared with their wild-type parents. Mutants formed short-branched, swollen septa-free hyphae (Fig. 2 ), which was different from typical $P$. erythroseptica hyphae and other oomycetes. Some mutants regained normal mycelial growth at $\mathrm{T} 2$, but others did not recover from the abnormal growth until

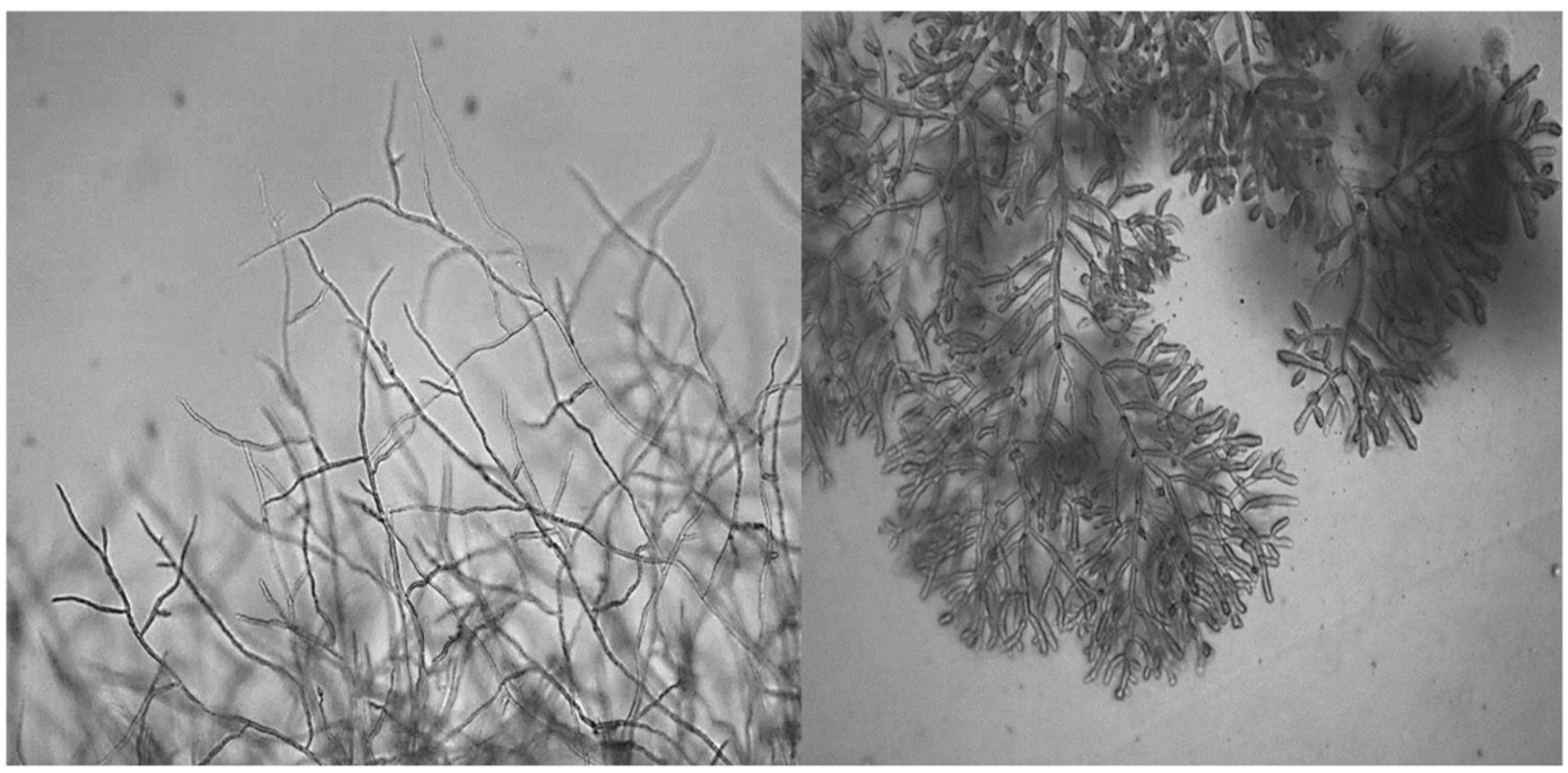

Fig. 2. Mycelial morphology of wild-type isolates (left) and the first generation of mutant Phytophthora erythroseptica $13 A 08$ (right). 
$\mathrm{T} 3$ or T4. Some mutants did not produce oospores between T3 and T6, but the oospore reproduction occurred in all the mutants at T8. One mutant stopped producing oospores at T5 and eventually died at T6. Multiple attempts to transfer this mutant from T4 and T5 failed.

Characterization of fluopicolide-resistant mutants of $\boldsymbol{P}$. erythroseptica. Spiral plating assay was conducted using the 10th transfer (T10) and the wild-type parents of all the mutants. $\mathrm{EC}_{50}$ values of mutants at the 10th transfer were significantly different from those of their parents. The type- 2 mutants were more resistant/tolerant to fluopicolide than the type-1 from the same parents, and it was observed that the type-2 mutants were not as resilient as type- 1 mutants, as type- 2 recovered more slowly on V8 plates at T1 (Table 1).

Mycelial growth of $\mathrm{P}$. erythroseptica mutants. The mutants grew significantly slower than their wild-type parents in the first $24 \mathrm{~h}$ (Table 2). The mycelial growth of each test isolate fit a linear regression model, with $R^{2}>0.9045$. Growth rates of mutants and their parents between 24 and $96 \mathrm{~h}$ were similar, except that the growth rate of mutant 13A14-M was lower than its wild-type parent (Table 3).

Pathogenicity of $\mathrm{P}$. erythroseptica mutants. All the fluopicolideresistant mutants were pathogenic to potato tubers, with a disease incidence of $100 \%$, except for mutant 13A14-M, with an incidence of $25 \%$ pink rot in the first tuber inoculation experiment. In terms of lesion size, most mutants were not significantly different from their corresponding wild-type parents, with the exceptions that mutants of 13A06-M and 13A14-M caused smaller lesions than the parents, and mutants of 13A07-M had greater lesion penetration than the parents (Table 4).

\section{Discussion}

All wild-type isolates of $P$. erythroseptica were sensitive to fluopicolide in this study. This result was not surprising as fluopicolide has not been broadly used in Maine, and the pathogen has not undergone a strong selection pressure. This is similar to the observations of Phytophthora capsici populations and Pseudoperonospora cubensis populations (Lu et al. 2011; Wang et al. 2014). However, this does not guarantee that there is no risk of resistance development in the future.

Table 2. Growth rate $(\mathrm{cm} / \mathrm{h})$ of mutants and corresponding wild-type parents of Phytophthora erythroseptica measured at $24 \mathrm{~h}$ of incubation

\begin{tabular}{lccccccc}
\hline Type $^{y}$ & 13A02 & 13A05 & 13A06 & 13A07 & 13A08 & 13A14 & 13A39 \\
\hline Wild-type & $0.96 \mathrm{a}^{\mathrm{z}}$ & $0.85 \mathrm{a}$ & $0.75 \mathrm{a}$ & $0.81 \mathrm{a}$ & $0.88 \mathrm{a}$ & $0.82 \mathrm{a}$ & $0.91 \mathrm{a}$ \\
Mutant-1 & - & $0.64 \mathrm{~b}$ & $0.60 \mathrm{~b}$ & $0.59 \mathrm{~b}$ & $0.61 \mathrm{~b}$ & - & $0.75 \mathrm{~b}$ \\
Mutant-2 & $0.53 \mathrm{~b}$ & $0.38 \mathrm{c}$ & - & - & - & $0.20 \mathrm{~b}$ & - \\
\hline
\end{tabular}

${ }^{\mathrm{y}}$ Mutant-1 indicates the type of mutants having $\mathrm{EC}_{50}$ higher but no more than

5 times that of wild-type parents. Mutant- 2 indicates mutants having $\mathrm{EC}_{50}$ over 5 times higher than the wild-type parents.

${ }^{\mathrm{z}}$ Mean values not connected by the same letters are significantly different $(P<0.05)$ within each column. "-" indicates no data were available.
The sensitivity of $P$. erythroseptica to fluopicolide varied in a skewed distribution. Mutants were derived only from 6 of 34 wildtype $P$. erythroseptica isolates. The estimated mutation frequency for fluopicolide resistance was approximately $10^{-5}$, which was lower than previously reported in other oomycete species (Lu et al. 2011; Wang et al. 2014), suggesting a low to moderate risk of fluopicolide resistance developing in P. erythroseptica populations (Brent and Hollomon 2007).

Morphological changes of fluopicolide-resistant $P$. erythroseptica mutants were observed, including misshapen hyphae. This may be associated with the delocalization of spectrin-like proteins (Toquin et al. 2008). Some mutants stopped producing oospores after three transfers (T3).

A trade-off between fluopicolide resistance and biological fitness in P. erythroseptica was observed in this laboratory study. Although the mutants were capable of infecting potato tubers, the virulence of mutants was generally reduced compared with their wild-type parents. In fact, the highly resistant (type-2) mutant had lower growth rates and virulence than the moderate resistant (type-1) mutant in the case of 13A05.

Our study of a relatively small number of isolates of $P$. erythroseptica indicated that some laboratory-generated mutants had impaired functions on various biological activities, which reduced their biological fitness, and may lead to reduced risk of fungicide resistance developing in the field. Therefore, the predicted risk of fluopicolide resistance in $P$. erythroseptica should be at a low to medium level. This result provided technical reference in fluopicolide application, which could be an alternative to mefenoxam in pink rot control. As fluopicolide has lower risk of resistance development, it is anticipated that fluopicolide can be broadly used with less concern than with mefenoxam. Regardless, for the best resistance management, fluopicolide should be incorporated in an integrated pest management program to reduce the risk of resistance development.

Table 4. Lesion penetration [(depth + width/2)/2] on potato tubers inoculated with Phytophthora erythroseptica mutants and their wild-type parents

\begin{tabular}{lccc}
\hline & \multicolumn{3}{c}{ Lesion penetration $(\mathbf{c m})$} \\
\cline { 2 - 4 } Isolate & Wild-type & Mutant-1 & Mutant-2 \\
\hline 13A02 & 3.96 & - & 3.06 \\
13A05 & 3.15 & 3.59 & 2.56 \\
13A06 & 3.89 & $2.98 * z$ & - \\
13A07 & 3.31 & $3.60 *$ & - \\
13A14 & 4.06 & - & $2.04 *$ \\
13A39 & 3.78 & 3.74 & - \\
\hline
\end{tabular}

$\mathrm{z} *$ Indicates a significant difference between the mutant and its parent $(P<$ $0.05)$ for each isolate. Mutant-1 indicates the type of mutants having $\mathrm{EC}_{50}$ higher but no more than 5 times that of their wild-type parents. Mutant- 2 indicates mutants having $\mathrm{EC}_{50}$ over 5 times higher than their wild-type parents.

Table 3. Growth rate ${ }^{y}$ (from 24 to $96 \mathrm{~h}$ incubation) of mutants and their wild-type parents of Phytophthora erythroseptica analyzed by linear regression

\begin{tabular}{|c|c|c|c|c|c|c|}
\hline \multirow[b]{2}{*}{ Isolate } & \multicolumn{2}{|c|}{ Wild type } & \multicolumn{2}{|c|}{ Mutant-1 ${ }^{z}$} & \multicolumn{2}{|c|}{ Mutant-2z } \\
\hline & Growth rate $(\mathrm{cm} / \mathrm{h})$ & $R^{2}$ & Growth rate $(\mathrm{cm} / \mathrm{h})$ & $R^{2}$ & Growth rate $(\mathrm{cm} / \mathrm{h})$ & $R^{2}$ \\
\hline $13 \mathrm{~A} 02$ & 0.0283 & 0.9972 & & & 0.0297 & 0.9945 \\
\hline $13 \mathrm{~A} 05$ & 0.0322 & 0.9860 & 0.0301 & 0.9045 & 0.0291 & 0.9985 \\
\hline $13 \mathrm{~A} 06$ & 0.0329 & 0.9975 & 0.0283 & 0.9913 & & \\
\hline $13 \mathrm{~A} 07$ & 0.0295 & 0.9929 & 0.0295 & 0.9929 & & \\
\hline $13 \mathrm{~A} 14$ & 0.0315 & 0.9981 & & & 0.0226 & 0.9933 \\
\hline 13A39 & 0.0288 & 0.9899 & 0.0296 & 0.9967 & & \\
\hline
\end{tabular}

${ }^{y}$ Growth rate is the slope of a regression equation generated by bivariate analysis.

${ }^{\mathrm{z}}$ Mutant- 1 indicates the type of mutants having $\mathrm{EC}_{50}$ higher but no more than 5 times that of wild-type parents. Mutant- 2 indicates mutants having EC ${ }_{50}$ over 5 times higher than the wild-type parents. 


\section{Literature Cited}

Al-Mughrabi, K. I., Peters, R. D., Platt, H., Moreau, G., Vikram, A., Poirier, R., and MacDonald, I. 2007. In-furrow applications of metalaxyl and phosphite for control of pink rot (Phytophthora erythroseptica) of potato in New Brunswick, Canada. Plant Dis. 91:1305-1309.

Benson, J. H. 2008. Effect of $\mathrm{Ca}$ and $\mathrm{pH}$ on Disease Severity of Pink Rot Phytophthora erythroseptica in Russett Norkotah Potato Solanum tuberosum. M.S. thesis, Brigham Young University. https://scholarsarchive.byu.edu/etd/ $1455 /$

Brent, K. J., and Hollomon, D. W. 2007. Fungicide-associated risk. Pages 6-11 in: Fungicide resistance: The assessment of risk. The Fungicide Resistance Action Committee.

Brown, J. K. M., and Rant, J. C. 2013. Fitness costs and trade-offs of disease resistance and their consequences for breeding arable crops. Plant Pathol. 62:83-95.

Choi, Y. W., Hyde, K. D., and Ho, W. H. 1999. Single spore isolation of fungi. Fungal Divers. 3:29-38.

Everitt, B. 1995. The analysis of repeated measures: A practical review with examples. Statistician 44:113-135.

Fiers, M., Edel-Hermann, V., Chatot, C., Le Hingrat, Y., Alabouvette, C., and Steinberg, C. 2012. Potato soil-borne diseases: A review. Agron. Sustain. Dev. 32:93-132.

Fitzpatrick-Peabody, E. R., and Lambert, D. H. 2011. Methodology and assessment of the susceptibility of potato genotypes to Phytophthora erythroseptica causal organism of pink rot. Am. J. Potato Res. 88:105-113.

Förster, H., Kanetis, L., and Adaskaveg, J. E. 2004. Spiral gradient dilution, a rapid method for determining growth responses and $50 \%$ effective concentration values in fungus-fungicide interactions. Phytopathology 94:163-170.

FRAC. 2018. FRAC Code List (*)2018: Fungicides sorted by mode of action. (including FRAC Code numbering). http://www.frac.info/docs/default-source/ publications/frac-code-list/frac_code_list_2018-final.pdf?sfvrsn=6144b9a_2

Goodwin, S. B., and McGrath, M. T. 1995. Insensitivity to metalaxyl among isolates of Phytophthora erythroseptica causing pink rot of potato in New York. Plant Dis. 79:967.

Jackson, K. L., Yin, J., Csinos, A. S., and Ji, P. 2010. Fungicidal activity of fluopicolide for suppression of Phytophthora capsici on squash. Crop Prot. 29:1421-1427.

Jiang, H. 2017. Biological and ecological behaviors of Phytophthora erythroseptica mediated by chemical signals. M.S. thesis. The University of Maine. https://digitalcommons.library.umaine.edu/etd/2737.

Kang, Y. S., and Park, W. 2010. Trade-off between antibiotic resistance and biological fitness in Acinetobacter sp. strain DR1. Environ. Microbiol. 12: 1304-1318.

Lambert, D., and Salas, B. 1994. Metalaxyl insensitivity of Phytophthora erythroseptica isolates causing pink rot of potato in Maine. Plant Dis. 78:1010.

Lu, X. H., Hausbeck, M. K., Liu, X. L., and Hao, J. J. 2011. Wild type sensitivity and mutation analysis for resistance risk to fluopicolide in Phytophthora capsici. Plant Dis. 95:1535-1541.

Matthews, J., Altman, D. G., Campbell, M., and Royston, P. 1990. Analysis of serial measurements in medical research. BMJ 300:230-235.
Mills, A., Platt, H., and Hurta, R. A. 2005. Salt compounds as control agents of late blight and pink rot of potatoes in storage. Can. J. Plant Pathol. 27:204-209.

Montarry, J., Corbière, R., and Andrivon, D. 2007. Is there a trade-off between aggressiveness and overwinter survival in Phytophthora infestans? Funct. Ecol. 21:603-610.

Pethybridge, G. H. 1913. On the rotting of potato tubers by a new species of Phytophthora having a method of sexual reproduction hitherto undescribed. Sci. Proc. R. Dublin Soc. 13:529-565.

Porter, L., Miller, J., Nolte, P., and Price, W. 2007. In vitro somatic growth and reproduction of phenylamide-resistant and-sensitive isolates of Phytophthora erythroseptica from infected potato tubers in Idaho. Plant Pathol. 56:492-499.

Rekanovic, E., Potocnik, I., Stepanovic, M., Milijašević-Marčić, S., and Biljana, T. 2008. Field efficacy of fluopicolide and fosetyl-Al fungicide combination (Profiler ${ }^{\circledR}$ ) for control of Plasmopara viticola (Berk. \& Curt.) Berl. \& Toni. in grapevine. Pestic. Phytomedicine 23:183-187.

Schisler, D. A., Slininger, P. J., Miller, J. S., Woodell, L. K., Clayson, S., and Olsen, N. 2009. Bacterial antagonists, zoospore inoculum retention time and potato cultivar influence pink rot disease development. Am. J. Potato Res. 86:102-111.

Taylor, R., Salas, B., Secor, G., Rivera, V., and Gudmestad, N. 2002. Sensitivity of North American isolates of Phytophthora erythroseptica and Pythium ultimum to mefenoxam (metalaxyl). Plant Dis. 86:797-802.

Taylor, R. J., Pasche, J. S., and Gudmestad, N. C. 2011. Effect of application method and rate on residual efficacy of mefenoxam and phosphorous acid fungicides in the control of pink rot of potato. Plant Dis. 95:997-1006.

Toquin, V., Barja, F., Sirven, C., and Beffa, R. 2008. Fluopicolide, a new antioomycetes fungicide with a new mode of action inducing perturbation of a spectrin-like protein. Pages 675-682 in: Modern Crop Protection Compounds. Wiley-VCH Verlag GmbH, Hoboken, NJ.

Toquin, V., Latorse, M. P., and Beffa, R. 2012:Pages 831-838 in: Modern Crop Protection Compounds. John Wiley \& Sons, Hoboken, NJ.

Torres-Londoño, G. A., Hausbeck, M. K., and Hao, J. J. 2016. ECX- an R package for studying sensitivity of antimicrobial substances using spiral plating technology. Plant Health Prog. 17:188-194.

Villa, N. O., Kageyama, K., Asano, T., and Suga, H. 2006. Phylogenetic relationships of Pythium and Phytophthora species based on ITS rDNA, cytochrome oxidase II and $\beta$-tubulin gene sequences. Mycologia 98:410-422.

Wang, W., Yan, L., Meng, R., Zhao, J., Zhang, X., Han, X., and Ma, Z. 2014. Sensitivity to fluopicolide of wild type isolates and biological characteristics of fluopicolide-resistant mutants in Pseudoperonospora cubensis. Crop Prot. 55:119-126.

White, T. J., Bruns, T., Lee, S., and Taylor, J. 1990. Amplification and direct sequencing of fungal ribosomal RNA genes for phylogenetics. Pages 315-322 in: PCR Protocols: A Guide to Methods and Applications.

Wicks, T., Davoren, C., and Hall, B. 2000. Fungicidal control of Phytophthora erythroseptica: The cause of pink rot on potato. Am. J. Potato Res. 77:233-240.

Zhang, X., Jiang, H., Johnson, S., Hao, J., Marangoni, N., and Zhang, X. 2016 Effects of chemical and biological products on pink rot of potato. (Abstr.) Phytopathology 106: S2.5. 